\title{
De la sociología de la literatura a la sociocrítica y a la estética sociológica*
}

Fecha de recepción: 8 de agosto de 2017

Fecha de aprobación: 14 de septiembre de 2017

\section{Resumen}

Se propone un breve recorrido por los aportes de los principales teóricos que influyeron en la conformación de campos de estudio desde los horizontes de la sociología de la literatura y las sociocríticas, con énfasis en los puntos de ruptura entre estas disciplinas y los desarrollos que estas trajeron. Finalmente, se introduce un nuevo desarrollo que se nutre de las dos: la estética sociológica, como un horizonte para la investigación literaria que entiende la literatura en relación con tres dimensiones en las que se arraiga: la lengua, el individuo y el grupo, con especial atención a su particularidad estética.

Palabras clave: sociología de la literatura; sociocrítica; estética sociológica; Lucien Goldmann; Mijaíl Bajtín; Julia Kristeva; Peter Václau Zima.

Citar: Pouliquen, H. (julio-diciembre de 2017). De la sociología de la literatura a la sociocrítica y a la estética sociológica. La Palabra, (31), 39-49. doi: https://doi. org/10.19053/01218530.n31.2017.727.

\section{Hélène Pouliquen}

Profesora e investigadora de la Maestría en Literatura del Instituto Caro y Cuervo; directora de la Línea en Investigación en Estética Sociológica. Licenciada en Letras Modernas, Universidad de La Sorbona, París. D.E.A. (Diploma en estudios profundos), Literatura hispanoamericana, Universidad de Montpellier III, Francia. helene.pouliquen@ caroycuervo.gov.co

* Artículo de reflexión en base a investigaciones realizadas durante la carrera académica. 


\section{la palabra}

\section{From Sociology of Literature to Sociocriticism and Sociological Aesthetics}

\section{Abstract}

This paper proposes a brief tour through the main contributions of the principal theorists who influenced the formation of fields of study in the horizons of Sociology of Literature and the different approaches of Sociocriticism, emphasizing on the breaking points between these disciplines and the developments brought about by them. Finally, a new development is introduced, which feeds from both: Sociological Aesthetics, as a horizon for literary research which understands literature in relation to the three dimensions in which is rooted: language, the individual and the collective, with special attention to its aesthetic particularity.

Key words: Sociology of literature; Sociocriticism; Sociological Aesthetic; Lucien Goldmann; Mihail Bakhtin; Julia Kristeva; Peter Václau Zima.

\section{De la sociologie de la littérature à la sociocritique et à l'esthétique sociologique.}

\section{Résumé}

Nous étudierons les concepts des théoriciens qui ont donné lieu à la création de la sociologie de la littérature et des sociocritiques. Nous analyserons les points de rupture entre ces disciplines ainsi que leurs contributions à la recherche en littérature. Finalement, nous nous intéresserons à l'esthétique sociologique qui, nourrie de la sociologie de la littérature et de la sociocritique, pense la littérature en rapport avec la langue, l'individu et le groupe, tout en mettant l'accent sur l'esthétique.

Mots-clés: sociologie de la littérature, sociocritique, esthétique sociologique, Lucien Goldmann, Mijaíl Bajtín, Julia Kristeva, Peter Václau Zima. 


\section{Goldmann, Bajtín y Kris- teva}

La sociología de la literatura (o estructuralismo genético, según su denominación científica) nace con Lucien Goldmann, en Francia, en la década de los cincuenta; se desarrolla durante unos quince años (de 1953 a 1968, aproximadamente) y cede el paso a la(s) sociocrítica(s), al principio de la década de los setenta.

Goldmann, nacido en Bucarest (Rumania), jurista de formación (Universidad de Bucarest y luego Universidad de Viena, bajo la dirección del marxista Max Adler), llega a la Universidad de París, en 1934, para estudiar economía política, literatura y filosofía. Siendo judío se ve obligado a refugiarse en un campo en Suiza, de 1942 a 1943. Con la ayuda del pedagogo Jean Piaget, recibe una beca para estudiar en la Universidad de Zurich, en donde termina su doctorado en filosofía, con una tesis en alemán titulada $E l$ hombre, la comunidad y el mundo en la filosofía de Immanuel Kant.

A diferencia de muchos otros izquierdistas franceses en las décadas de los cincuenta y los sesenta, marcados por la preeminencia del estructuralismo linguístico de la Escuela de París, 0, en el Quartier latin, la zona de los intelectuales y artistas cuyo centro es la Sorbona antigua y las múltiples librerías que la rodean, generó un cuestionamiento y hasta una antipatía severa, despectiva a veces, hacia Goldmann y su obra, en el campo reunido alrededor de la revista Tel Quel (Philippe Sollers, Julia Kristeva y varios otros, entonces formalistas sofisticados).

Tomaré el ejemplo de Julia Kristeva quien, con un artículo publicado en 1967 (dos años después de su arribo a París a donde llegó de Sofía, Bulgaria, su lugar de nacimiento en 1941) titulado «Bajtín, la palabra, el diálogo y la novela», introduce en Francia al teórico ruso de la literatura (y de manera privilegiada, de la novela) de principio del siglo XX, opuesto a la famosa corriente del formalismo ruso. El grupo de Bajtín, que incluye, entre otros, a Medvedev -quien se interesa por el psicoanálisis naciente- y Voloshinov -quien tiende hacia el marxismo- es perseguido por el nuevo régimen soviético de Lenin, pero, sobre todo, por el de Stalin. Ni Medvedev ni Voloshinov escaparon a las purgas de Stalin. Bajtín, víctima de una grave enfermedad de los huesos, no será sentenciado a muerte sino exiliado a una universidad de provincia y sus trabajos, infravalorados.

Es necesario subrayar que, la hostilidad declarada de Bajtín al formalismo no significa el desconocimiento del rol de la palabra en la transmisión de la axiología (social) en el texto (lingüístico). De hecho, Bajtín distingue dos niveles en el mensaje de un texto literario: la forma composicional y la forma arquitectónica, según la cercanía del análisis al material lingüístico -composicional- o al mensaje global -arquitectónico-. El término 'forma' no se toma tampoco en el sentido tradicional, designado por Bajtín por la expresión de material verbal, opuesto a los términos de 'contenido' y de 'forma' (el nivel esencial). Por otro lado, el formalismo ruso no tuvo nunca la intención de limitar el análisis literario al nivel lingüístico o semiológico: ese nivel no era concebido sino como la base y luego se desarrollaría un análisis axiológico (como lo realizará, en particular, Yuri Lotman). Precisemos, finalmente, que las simpatías de Stalin iban hacia al formalismo (con toda seguridad, por su ideología arbitraria no deseaba enfrentarse a la lucidez generalizada).

Los conceptos centrales de Bajtín, subrayadas por Kristeva en su artículo de 1967, son los conceptos hoy ya famosos y muy difundidos de carnaval, discurso carnavalesco, lógica otra (una lógica diferente de la lógica científica), dialogismo, ambivalencia, novela polifónica y discurso monológico. Kristeva, a partir de Bajtín, propone temáticas como el monologismo épico o, en oposición, el 
carnaval, la homología cuerpo - sueño - estructura lingüística

- estructura del deseo, el diálogo socrático, el monologismo como aniquilación de la persona, la Menipea y el texto como actividad social y, finalmente, la novela subversiva.

Kristeva propone en este texto, unos elementos de reflexión esenciales a la(s) sociocrítica(s), si bien nunca empleó el término; y si estuvo cerca de un grupo, fue del grupo alrededor de la revista Tel Quel, más bien formalista y en el cual la introdujo Philippe Sollers, con quien se casó para tener acceso al seguro social francés.

Veamos algunos puntos de ese artículo:

1- De acuerdo con Kristeva (1967):

Si la eficacia científica en el campo de las ciencias humanas siempre ha sido cuestionada es notorio que, por primera vez, este cuestionamiento se hace ahora al nivel mismo de las estructuras estudiadas que obedecerían a una lógica otra que la lógica científica [...] Dos posibilidades se ofrecen entonces a la Semiología literaria: el silencio y la abstención o la insistencia sobre el esfuerzo para elaborar un modelo isomorfo a esta lógica otra (p. 438).

2- Kristeva evidencia cómo Bajtín realiza "una de las tentativas más poderosas" de superación de la posición del formalismo ruso:

Bajtín es uno de los primeros en sustituir el recorte estático de los textos por un modelo en el cual la estructura literaria no es sino en donde se elabora con relación a otra estructura. Esta dinamización del estructuralismo no es posible sino a partir de una concepción según la cual la 'palabra literaria no es un punto (un sentido fijo) sino un cruce de superficies textuales, un diálogo de varias escrituras: del escritor, del destinatario (o del personaje), del contexto actual o anterior [...] Bajtín sitúa el texto en la historia y la sociedad considerada en sí mismas como textos que el escritor lee y en los cuales se inserta re-escribiéndolos [...] la única manera que tiene el escritor de participar en la historia es entonces la transgresión de esta abstracción [que es la historia lineal] por una escritura-lectura, es decir por la práctica de una estructura significante en función de o una oposición a otra estructura. La historia y la moral se escriben y se leen en la infraestructura de los textos. Así, polivalente y plurideterminada, la palabra poética sigue una lógica que supera la lógica del discurso codificado y que no se realiza plenamente sino al margen de la cultura oficial (p. 439).

Si bien Kristeva no lo dice, aquí está oponiendo el estatismo básico en la conexión estructura del texto (o, a otro nivel, visión del mundo, en el estructuralismo genético de Goldmann) con el texto mismo, a la dinamización (valorada) en la conceptualización de Bajtín, presentada como una poderosa superación del formalismo ruso (lo que es también, por supuesto).

3- Enseguida, Kristeva opone la cultura oficial al carnaval, como el elemento fundamental del pensamiento bajtiniano. El carnaval es la figura y el momento ${ }^{1}$ con el cual Bajtín renovó la reflexión sobre la cultura. Kristeva afirma:

El discurso carnavalesco rompe las leyes del lenguaje censurado por la gramática y la semántica, y de esta manera es un cuestio-

\footnotetext{
${ }^{1}$ Sabemos que Bajtín subrayó que, en las sociedades tradicionales, más de la mitad del tiempo, el orden oficial se veía volteado en orden carnavalesco, dominado por el rey del carnaval, un loco o un -o una-idiota, según la reflexión aportada por el intelectual Michel de Certeau y también por la novelista Marguerite Duras.
} 
namiento social y político; no se trata de equivalencia sino de identidad entre el cuestionamiento del código lingüístico oficial y el cuestionamiento de la ley oficial (p. 439).

4 Terminaré este sobrevuelo rápido, de un texto esencial para la superación del estructuralismo genético goldmaniano, con la evocación del concepto de ambivalencia, que Kristeva plantea como esencial, por lo menos, en dos momentos de su análisis. Veamos:

\subsection{Nos propone una definición} del término en conjunción con los términos de diálogo (o dialogismo), de polifonía, de monologismo, de Menippée (a partir de la famosa sátira menipea de la Antigüedad como modelo de cuestionamiento de la literatura oficial), invitándonos a considerar, con Bajtín:

La escritura como lectura del corpus literario anterior, el texto como absorción de y réplica a otro texto (la novela monológica como anulación de la estructura literaria que por su dialogismo Bajtín llama la "menipea" [...] El diálogo y la ambivalencia se revelan así ser el único modo que permite al es- critor entrar en la historia profesando una moral ambivalente, la de la negación como afirmación (p. 444).

Vemos aquí introducirse en el panorama conceptual la impronta de la dialéctica negativa de Adorno, la cual tendrá cada vez más peso en la(s) sociocrítica(s).

4.2. En la conclusión de su artículo, Kristeva retoma la problemática de la ambivalencia afirmando que:

El término 'ambivalencia' se adapta perfectamente al estadio transitorio de la literatura europea, la cual es una coexistencia (una ambivalencia) a la vez «doble de lo vivido» (realismo, épico) y el «vivido» mismo (exploración lingüística, menipea) antes de desembocar, tal vez, en una forma de pensamiento semejante al de la pintura: transmisión de la esencia por la forma, configuración del espacio (literario) como revelador del pensamiento (literario) sin pretensión 'realista' [...] El dialogismo, más que el binarismo, sería tal vez la base de la estructura intelectual de nuestra época. (p. 464).

Ahora bien, Goldmann, al final de un texto de 1968 (dos años antes de su muerte en 1970), se propone sintetizar definitivamente su concepción de la rela- ción literatura/sociedad al tiempo que se muestra dispuesto (en la conclusión a la cual quiero aludir) a ampliar, si no a modificar, su teoría del estructuralismo genético, es decir, dispuesto a un diálogo con Kristeva y Bajtín. Subraya que no ha leído a Bajtín, ya que no lee el ruso y el teórico no ha sido traducido todavía, y que su principal meta al elaborar su teoría fue la de superar e incitar a superar el impresionismo en el análisis literario, pero que está abierto a todos los desarrollos interesantes sugeridos en cuanto a la elaboración de la relación literatura/sociedad.

Su actitud frente a Julia Kristeva es muy abierta y empática: Kristeva fue su discípula, así como de Roland Barthes, en la Escuela de Altos Estudios en París, en donde obtuvo su doctorado en literatura bajo su dirección. La novela autobiográfica de Kristeva (1990), Los samuraïs, da, sin embargo, si bien una imagen muy grata de Roland Barthes, una imagen mucho menos amable de Lucien Goldmann. Kristeva publicó su tesis de doctorado, El texto de la novela, en $1970 \mathrm{y}$, si bien se siente la influencia de Lucien Goldmann, esta es mucho menos notoria que su opción por la lingüística transformacional. Más adelante, como lo analicé en otro texto, la sociocrítica de Kristeva se hizo mucho más psicoanalítica a la vez que subversiva frente a la sociedad, 
como en el texto publicado por la librería Arthème Fayard en 1996 con el título de Sentido y sin sentido de la revuelta. Poderes y límites del psicoanálisis I. Kristeva misma, después de haber sido linguiista y crítica literaria, se dedicó profesionalmente al psicoanálisis clínico.

\section{Zima}

Sin embargo, el paso de la sociología de la literatura a un tipo de sociocrítica es todavía más claramente diseñado, en mi opinión, en el caso del intelectual de origen checo Peter Václau Zima, nacido en Praga, profesor emérito en la Universidad de Klagenfurt en Austria y miembro de la Academia Europea en Londres, quien escribe tanto en alemán como en inglés y francés, y ha hecho un aporte notorio a la teoría de la evolución de la novela europea del siglo XIX al siglo $\mathrm{XX}$.

Dentro de la muy amplia obra de P. V.Zima, localizaré un momento muy significativo de su recorrido para la problemática que me interesa aquí: la evolución de la sociología de la literatura a la sociocrítica en cuanto al análisis de la novela. En febrero de 1973, Zima publica, en las Ediciones Nizet, en París, un libro titulado Le désir $d u$ mythe. Una lectura sociológica de Marcel Proust. Agradece al profesor Lucien Goldmann, su director de tesis, que «le ayudó a aplicar el método del estruc- turalismo genético a la interpretación de la obra proustiana». Agrega un agradecimiento a M. Jacques Leenhardt (autor de una Lectura política de la novela $\mathrm{La}$ celosía de Alain Robbe-Grillet, publicado en la colección Critique de las Editions de Minuit, ligadas al grupo Tel Quel, ya mencionado, en diciembre de 1972), «siempre listo a discutir conmigo los problemas de mi trabajo, quien me ha sido de gran ayuda, sobre todo después de la desaparición de Lucien Goldmann».

Después de este abordaje goldmaniano de la obra de Proust, Zima publica, en 1980, en la colección Argumentos críticos de la editorial Le Sycomore, ya desaparecida, otro análisis de Proust, apoyado esta vez en la filosofía de T. W. Adorno. La colección, dirigida por Reginaldo Di Piero, brasileño, investigador en el grupo de sociología de la literatura en la Escuela de Altos Estudios en París, es presentada por el director Di Piero como «una colección abierta, pluridisciplinaria, que tratará de presentar al público francés textos importantes en el campo de las ciencias humanas en una perspectiva dialéctica». Di Piero (1980) agrega que «lo esencial es mantener una relación critica permanente con la realidad y contribuir a su transformación».

El texto mismo de Zima, en su índice, designa la nueva dis- ciplina por la fórmula que el crítico, al principio, prefiere y trata de imponer: la sociología del texto literario. Es, tal vez, una formulación más adecuada: indica el origen de la reflexión, la sociología de la literatura, subrayando la particularidad del nuevo enfoque, la insistencia en la atención llevada al texto mismo, y no a su estructura, a la vez que el distanciamiento respecto a Goldmann. Pero, como siempre, la denominación más compacta se impone, aunque sea menos adecuada: Zima, en 1985 dará como título a su nuevo libro, el de Manual de Sociocrítica.

Enseguida, Zima desvela, agresivamente (escribirá más de un texto que cuestiona, con rudeza, el estructuralismo genético y en la famosa confrontación Goldmann / Adorno se decidirá rotundamente por Adorno) su cuestionamiento del maestro antes reverenciado. Habla de la sociología de la literatura como «reificación del texto» y propone «una crítica de la sociología de la novela».

En cuanto a la conexión literatura / sociedad, analiza la situación linguística bajo la Tercera República francesa, momento histórico en el cual se forma Marcel Proust y se gesta su novela. Zima insiste sobre el efecto de la economía de mercado sobre el lenguaje, introduce el concepto de sociolecto, lo pone en relación con el concepto de 
discurso y propone su hipótesis para el análisis de la novela de Proust: plantea la conversación (mundana) como sociolecto de la clase de ocio, a la cual Proust el dandy pertenece, y subraya finalmente cómo la novela de Proust inicia una crisis de la novela en relación con la novela realista de Balzac, situando la novela en un nuevo momento de la Modernidad.

Zima introduce, también, al lado del concepto de ambigüedad (que marca todos los géneros dialógicos señalados por Bajtín, y las posiciones menipeas cuestionadoras del poder, carnavalescas, desde la antigüedad), los conceptos de ambivalencia y de indiferencia, más particulares al análisis y la historia de la novela. El crítico propone, en cuanto a la evolución de la novela en Europa, a partir de la crisis del realismo cuyo modelo sería Balzac, dos etapas: la etapa de la ambivalencia novelesca (1890-1930), ilustrada por la novela de Proust, Kafka y el austriaco Musil, y en la cual, después de la conceptualización ya analizada, Zima propone, a partir del análisis central de la obra de Proust, varias 'digresiones' hacia Kafka y Musil, y una apertura hacia el surrealismo, llegando a plantear «la disyunción absoluta y el fin de la novela» (p. 359).

El crítico concluye su análisis planteando el problema de la recepción de En busca del tiempo recobrado (la novela de Proust) en la teoría critica de Adorno, haciendo énfasis sobre la crítica de la comunicación y el famoso ensayo de Adorno sobre el poeta loco Hölderlin, titulado Parataxis y publicado en Notas sobre la literatura (1960-61).

La segunda etapa, según Zima, de la evolución de la novela europea, que cubriría la primera mitad del siglo XX; la ilustra con la novela La náusea de Jean Paul Sartre, Los indiferentes del italiano Moravia y El extranjero de Albert Camus. La nueva etapa sería marcada por una agravación de la ambivalencia, la indiferencia, y se focaliza en la crisis acelerada del sujeto, manifiesta en una crisis de la narración. El análisis se centra en los mecanismos discursivos de la ideología y la crítica de los sociolectos. Zima retoma y profundiza aquí el concepto elaborado en el tomo anterior, el de la ambivalencia novelesca, concepto que permite situar la relación literatura/sociedad al nivel de los códigos lingüísticos extratextuales y la expresión textual misma, y no al nivel del pensamiento, de las estructuras significativas, de las visiones del mundo textuales y extratextuales, como lo propone Goldmann.

De la misma manera que en cuanto a la obra de Proust, lo que se pone en relación con el texto literario es la conversación burguesa, calificada de $s o$ - ciolecto ambivalente, se subraya el abismo que se abre cada vez más entre el ser y el parecer. Así como el título de la novela de Moravia La indiferencia sugirió a Zima la categoría de la indiferencia, esta se analiza al nivel del lenguaje, en el que las disyunciones, origen de un sentido claro e imperativo, se van borrando como los valores cristianos o humanistas que las generaban, y cuya crítica es la meta de los nuevos textos novelescos. ¿Debemos ver una contradicción en el epígrafe del volumen, una afirmación de Jean Guehenno, muy enfática, que lamenta la consecuencia de la erosión de la disyunción, paulatina desde la premodernidad, y la pérdida de los valores a lo largo de la modernidad: "¿el peor de los horrores es el no sentido"?

De manera muy lógica, el análisis arranca con la crítica de los sociolectos humanistas, que es el objetivo central de Sartre en La náusea, que propone un cuadro diverso de la cosificación humana. Luego, el análisis se dirige hacia Los indiferentes y La desobediencia de Moravia, en las que la crisis del sujeto y de la narración se ilustra también, de otra manera. Finalmente, Zima llega a la reificación en El extranjero de Camus y propone una definición, o por lo menos, un acercamiento suficiente a la novela existencialista e indica el camino hacia 
el anti-humanismo radical de la Nueva Novela.

De la obra subsiguiente de Zima, subrayaré su Manual de Sociocrítica (Picard, París, 1985) obra de síntesis, constituida de textos traducidos del alemán y aumentados, por lo esencial. En relación con lo que ya he analizado de la sociocrítica de Zima, debo notar una sistematización notoria de métodos y modelos, una profundización de nociones sociológicas fundamentales (subrayaría algunas, como conciencia colectiva, normas y valores anomia, conciencia de clase e ideología, ideología y ciencia, ideología y mediación por el valor de cambio, reificación y alienación, en mi sentido, particularmente útiles) y el establecimiento de los límites entre sociología y filosofía, y sociología y psicología.

Adicionalmente, Zima recuerda los conceptos centrales de la reflexión y el método de Lukács, Goldmann, Adorno y Pierre Macherey.

También, aborda la sociología de los géneros literarios: el drama y la tragedia, el texto lírico, la novela, en las obras de Goldmann, Leo Löwenthal, Adorno, Walter Benjamin, Lukács, Macherey y Bajtín.

Finalmente, propone una sociología de la Nueva Novela anunciada en $\mathrm{La}$ indiferencia novelesca con el análisis de $E l$ voyerista de Alain Robbe-Grillet. Además, introduce la problemática sociocrítica y psicoanálisis, que ya había sido planteada por Jacques Leenhard en 1973 con el análisis de otra novela de Robbe-Grillet, La celosía. En este caso, se trata de «sociedad y psiquis en Marcel Proust». Zima concluye su volumen abordando la problemática de la estética de la recepción (la teoría de la lectura del Círculo lingüístico de Praga y la Escuela de Constanza). Menciona también aquí los trabajos de Robert Escarpit, Joseph Jurt, Jacques Leenhardt, Youri Lotman y Hans Robert Jauss.

Para concluir, me alegra señalar que, si bien los trabajos de Zima sobre la novela -La ambivalencia novelesca y La indiferencia novelesca- siguen sin traducción en español, Para una sociología del texto literario (del 2010) y Manual de Sociocrítica (del 2013) están disponibles gracias a la traducción editada por el Instituto Caro y Cuervo.

\section{Estética sociológica}

Mientras el Seminario Andrés Bello del Instituto Caro y Cuervo estuvo cerrado, esto es, durante siete años, se dio la ocasión de hacer un balance de la evolución de las líneas de investigación, además de acentuar un giro hacia la investigación misma, que debería estar integrada de manera muy estrecha con los procesos de enseñanza. En mi caso, esto significó la elaboración de una hipótesis para un proyecto de investigación acerca de un tipo de novela que designé como la novela del encanto de la interioridad, diferente de los tres tipos de novela definidos por el joven Lukács en su famosa Teoría de la novela (1920), tres tipos frutos de un escepticismo más o menos radical, que relaciono con problemas familiares e históricos, además del género de su autor. La novela del encanto de la interioridad, sería analizada en relación con un momento histórico y un tipo de sociedad, pero también en relación con el género (un tipo humano más o menos varonil o feminil dado que, como nos lo recuerda Julia Kristeva, pero ya lo había establecido Freud, la bisexualidad caracteriza al ser humano y la disyunción radical de los sexos, esquizofrénica, no puede sino llevar a la guerra eterna entre ellos) y la intimidad más profunda del escritor (o escritora) accesible solo con un conocimiento del psicoanálisis actualmente muy extendido. Dada esta nueva circunstancia histórico-cultural, el análisis de la obra literaria, en el caso mío, de la novela, debe hacerse en un marco más amplio, no reducido a la problemática literatura/ sociedad, un marco que debe recentrarse en la problemática esencial, la problemática estética. La disciplina debe ser la Estética. Pero no se quiere volver a la estética clásica o anti- 
gua, de Kant y Hegel o de Platón y Aristóteles ¿Cómo evitar que la palabra obligue a hacer un recorrido no deseado? Con un calificativo como 'histórica' o 'sociológica'. Supongo que, finalmente, la sociología de la literatura o las sociocríticas me llevaron, por fidelidad a opciones tempranas, a la estética sociológica.

Sería entonces una nueva disciplina sin un método tan claro y rígidamente establecido como el estructuralismo genético de Goldmann, el cual se niega a considerar al individuo creador como instancia múltiple y compleja.

Esta disciplina se alimentará de otro estructuralismo genético, el psicoanálisis de Freud (de Lacan, de Melanie Klein, de Kris- teva, de Denise Braunsweig), el cual ubica la génesis del texto en las capas inconscientes o no conscientes del individuo creador, quien a su vez se construye en diálogos múltiples con su entorno natural, familiar, social, histórico, su país, la historia, su lengua.

El programa es inmenso: aprender a considerar el trípode que sostiene la obra literaria, la lengua, el individuo, el grupo, sin olvidar su particularidad estéti$c a$ (no es un texto comunicativo o político en el sentido banal). Por lo pronto, con el grupo que se va ampliando con las diversas promociones de estudiantes del I.C.C y el trabajo que se va realizando con múltiples tesinas y artículos, la tarea inmediata es la construcción, a partir de novelas particulares, de las figuras diversas y complejas del encanto de la interioridad.

A pesar de los problemas del mundo, no perdemos la esperanza de conectar, de manera grata o menos grata, pero de manera honesta, lo menos reificada posible, con nuestro ser profundo.

Finalmente, me permito anunciar un libro titulado La novela del encanto de la interioridad. Literatura, filosofía, psicoanálisis, que será publicado en co-edición entre la Editorial de la Universidad Javeriana y la Editorial del Instituto Caro y Cuervo y, lanzado en la próxima Feria del libro. Allí podrán encontrar más desarrollos acerca de la disciplina (la línea) estética sociológica.

\section{Referencias}

Adorno, T. W. (1962). Notas de literatura. Barcelona: Ariel.

Adorno, T. W.(1983 [1971]). Teoría estética (F. Riaza, Trad.). Barcelona: Ediciones Orbis.

Altamirano, C., \& Sarlo, B. (1983). Literatura / Sociedad. Buenos Aires: Hachette.

Bajtín, M. M. (1989 [1975]). Teoría y estética de la novela (H. S. Kriukova y V. Cazcarra, trad.). Madrid: Taurus.

Bajtín, M. M. (1986 [1924]). El problema del contenido, del material y de la forma en la creación artística verbal. En Problemas literarios y estéticos (A. Caballero, trad.). La Habana: Arte y Literatura. 
Goldmann, L. (1956). La Communauté Humaine el l'Univers chez Kant. (trad. al español : La comunidad humana y el universo en la obra de Kant).

Goldmann, L. (1959). Le dieu caché. Étude sur la vision tragique dans les pensées de Pascal et dans le théâtre de Racine. Bibliothèque des idées, Gallimard, París. (trad. al español: El hombre y lo absoluto).

Goldmann, L. (1964). Pour une sociologie du roman. Gallimard., París. (trad. al español : Para una sociología de la novela).

Goldmann, L. (1968). Sociologie de la création littéraire. Revue Internationale des Sciences Sociales, 19(4), París.

Kristeva, J. (1967). Bakhtine, le mot, le dialogue et le roman. Critique, (239). (trad. al español: Bajtin, la palabra, el diálogo y la novela).

Kristeva, J. (1970). Le texte du roman. Approche sémiologique d'une structure discursive transformationelle. The Hague - París- New York: Mouton Publishers. (trad. al español por Jordi Llovet: El texto de la novela, Lumen, Barcelona, 1981).

Kristeva, J. (1990). Les Samuraïs. París: Arthème Fayard. (trad. al español Los Samurais. Plaza \& Janes, Barcelona, 1990. Trad. de Xavier Gispert).

Kristeva, J. (1996). Sens et non-sens de la révolte. París: Pouvoirs et limites de la psychanalyse I. Fayard. (trad. al español Sentido y sinsentido de la revuelta. Literatura y psicoanálisis. Eudeba, Buenos Aires, 1998).

Leenhardt, J. (1973). Lecture politique du roman: La jalousie d'Alain Robbe-Grillet. París: Editions de Minuit. (trad. al español Lectura política de la novela: La celosía de Alain Robbe-Grillet).

Pouliquen, H. (1992). Teoría y análisis sociocríticos. Bogotá: Universidad Nacional de Colombia.

Zima, P. V.(1973). Le Désir du mythe: une lecture sociologique de Marcel Proust. Nizet, París: Editions A.-G.

Zima, P. V. (1978). Pour une Sociologie du texte littéraire. París: Picard. (Traducción al español por Camilo Sarmiento Jaramillo: Para una sociología del texto literario, Instituto Caro y Cuervo, Bogotá, 2010).

Zima, P. V. (1980). L’ambivalence romanesque: Proust, Kafka, Musil. París: Le Sycomore.

Zima, P. V. (1982). L 'indifférence Romanesque. Sartre, Moravia, Camus. París: Le Sycomore. 
Zima, P.(1985). Manuel de sociocritique. París: Picard. (traducción al español por Alfonso Correa: Manual de sociocrítica, Instituto Caro y Cuervo, Bogotá, 2013). 